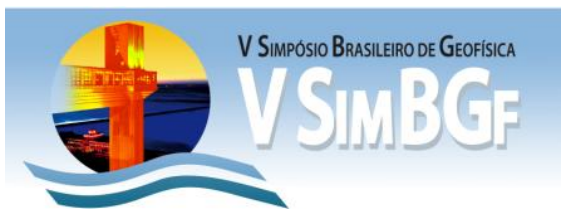

\title{
Otimização de sensores magnéticos fluxgate nanocristalinos e amorfos usando o sistema LabView.
}

\author{
Patricia F. O. Rosa, Luiz Benyosef e Felipe Silva* - Observatório Nacional, National Instruments(*)
}

Copyright 2012, SBGf - Sociedade Brasileira de Geofísica

Este texto foi preparado para a apresentação no V Simpósio Brasileiro de Geofísica, Salvador, 27 a 29 de novembro de 2012 . Seu conteúdo foi revisado pelo Comitê Técnico do V SimBGf, mas não necessariamente representa a opinião da SBGf ou de seus associados. É proibida a reprodução total ou parcial deste material para propósitos comerciais sem prévia autorização da SBGf.

\section{Resumo}

Visando aprimorar as propriedades magnéticas dos elementos sensores - amorfos e nanocristalinos utilizado nos magnetometros do tipo fluxgate, desenvolvidos no $\angle D S M / O N$, construímos um Histeresímetro Virtual usando a Linguagem de Programação Gráfica LABVIEW para caracterização de curvas de magnetização objetivando a otimização os sensores de alta resolução.

Este trabalho aborda a visualização gráfica, plotagem e caracterização do ciclo de histerese, a medição e caracterização do campo magnético e do fluxo magnético para núcleos dos sensores fluxgate amorfos e nanocristalinos.

\section{Introdução}

O sensor fluxgate basicamente consiste de um núcleo construído com material ferromagnético, de alta permeabilidade, com duas bobinas, de excitação e outra para detecção. Alinhando o eixo longitudinal do sensor com a direção de um campo magnético e excitando-o com um sinal de corrente periódico, o núcleo será magnetizado alternadamente, com o aparecimento de um fluxo magnético $(\phi=$ B.A $)$. Nestas condições a permeabilidade relativa $\left(\mu_{\mathrm{r}}\right)$ do núcleo sofre uma alteração acompanhando a variação do fluxo magnético associado, e um sinal de tensão $\mathrm{V}_{\text {sec }}$ será induzido nas "n" espiras da bobina sensora.

$$
V_{s e c}=n_{s} A B \text { ex }(1-D) \frac{\left(d \mu_{r} / d t\right)}{\left[1+D\left(\mu_{r}-1\right)\right]^{2}}
$$

Tradicionalmente, desde o seu aparecimento, os núcleos são construídos com materiais magnéticos cristalinos, de base $\mathrm{NiFe}$, do tipo Permalloy, Ferrite e mu-metal. Posteriormente, desde meados da década de 1980, uma nova opção de materiais surgiu como alternativa para substituir os materiais cristalinos tradicionais. Foram os materiais magnéticos amorfos de base cobalto.

Os ruídos de magnetostricção são de importância fundamental na escolha dos materiais para sensores fluxgate tanto amorfos quanto nanocristalinos. Na prática, deve-se optar por materiais que apresentem menores níveis de coeficiente de magnetostricção alem de curvas de histerese mais estreitas, o que corresponde à materiais com força coerciva de pequena intensidade. A determinação precisa das curvas de magnetização dos materiais é fator determinante para a obtenção de sensores de alta resolução.

O LabView (Laboratory Virtual Instrument Engineering Workbench) foi usado neste projeto por tratar-se de uma poderosa ferramenta, desenvolvida pela National Instruments.

Este trabalho tem como objetivo a visualização gráfica, plotagem e caracterização do ciclo de histerese, a medição e caracterização do campo magnético e do fluxo magnético para núcleos dos sensores fluxgate amorfos e nanocristalinos, usando o LabView (Laboratory Virtual Instrument Engineering Workbench).

\section{Descrição do projeto}

O projeto consistiu em uma placa de aquisição de dados fabricada pela National Instruments, NI PCl-6230, resolução de 16 bits, oito entradas e quatro saídas analógicas de 16 bits, taxa de amostragem de 500000 amostras por segundo e o software utilizado LabView, versão 9.0.

O enrolamento primário é excitado através de um sinal senoidal gerado pela própria placa de aquisição de dados NI PCl-6230 com a freqüência do sinal de excitação variando de $1 \mathrm{KHz}$ a $20 \mathrm{KHz}$ com amplitude de 5 volts. A corrente de entrada determina o campo magnético $\mathrm{H}$ e é lido através de um resistor $\mathrm{R} 1$. A tensão sob o resistor $\mathrm{R} 1$ é proporcional a corrente de excitação.

A visualização gráfica desse sinal é plotado no eixo $x$ em um gráfico $X Y$ em unidades de amperes-volts por metro.

O enrolamento secundário também é conectado a placa de aquisição de dados e através de um integrador RC no software LabView, a tensão de saída é integrada e proporcional à densidade de fluxo magnético $B$ em unidades de tesla para o eixo y do gráfico $X Y$.

As impedâncias da placa de aquisição de dados e a bobina devem ser levadas em consideração utilizando um buffer com alta impedância de entrada e baixa impedância de saída

O software LabView vincula a criação de interfaces com o usuário (chamado painéis frontais) no ciclo de desenvolvimento. Programas e/ou sub-rotinas em LabView são chamados de instrumentos virtuais (VIs). Cada VI tem três componentes: um diagrama de blocos, um painel frontal e um painel de conector.

Este último é usado para representar o VI nos diagramas de blocos de outra, chamando VIs. Controles e indicadores no painel frontal permite que um operador adicione dados ou extraia dados de um instrumento virtual em execução. No entanto, o painel frontal também pode servir como uma interface de programação. Assim, um instrumento virtual pode ser executado como um 
programa, com o painel frontal servindo como uma interface de usuário, ou como um nó para o diagrama de bloco. O painel frontal define as entradas e saídas para o nó dado através do painel de ligação. Isto implica que cada VI pode ser facilmente testado antes de ser incorporado como uma sub-rotina em um programa maior.

A abordagem gráfica também permite que não programadores possam construir programas, arrastando e soltando representações virtuais de equipamentos de laboratório com os quais já estão familiarizados.

O ambiente de programação LabView, com os exemplos incluídos e documentação, torna simples a criação de pequenas aplicações. Isto é um vantajoso de um lado, mas também há um certo risco de subestimar o conhecimento necessário para a linguagem de programação $\mathrm{G}$.

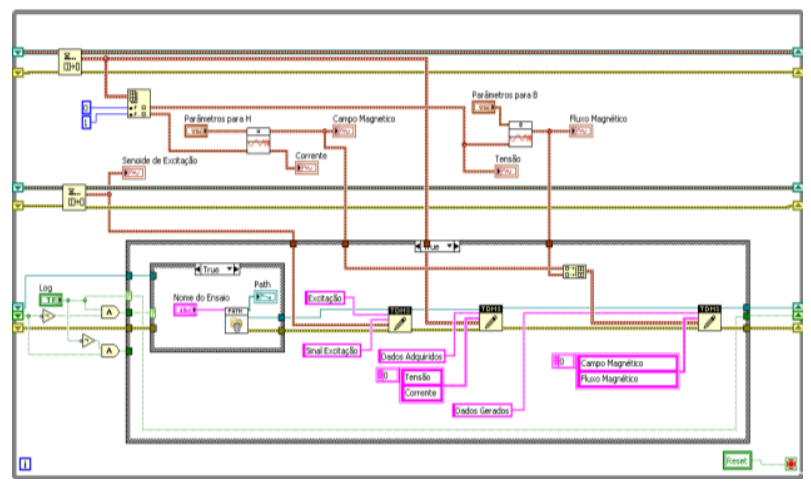

Figura 1 - Esquemático LabView para simular medições de histerese em sensores de magnetometros fluxgate.

Para algoritmos complexos ou de grande escala de código, é importante que o programador possua um amplo conhecimento da sintaxe LabVIEW especial e a topologia do seu gerenciamento de memória.

Os mais avançados sistemas LabVIEW desenvolvidos oferecem a possibilidade de construir aplicações standalone. Além disso, é possível criar aplicações distribuídas, que se comunicam por um sistema de cliente / servidor, portanto, mais fácil de implementar, devido à natureza inerentemente paralela de programação $\mathrm{G}$.

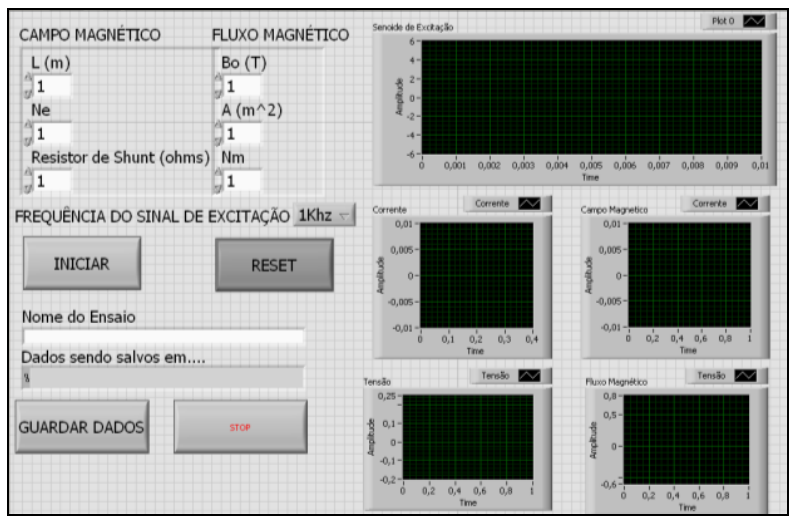

Figura 2 - Indicadores para monitorar parâmetros a serem observados para determinação de curvas de magnetização.

\section{Resultados}

Os resultados mostram-se animadores. Foram obtidas as primeiras curvas de magnetização que serão fundamentais para o desenvolvimento de sensores fluxgate de alta resolução, como esta mostrada na figura 3 abaixo.

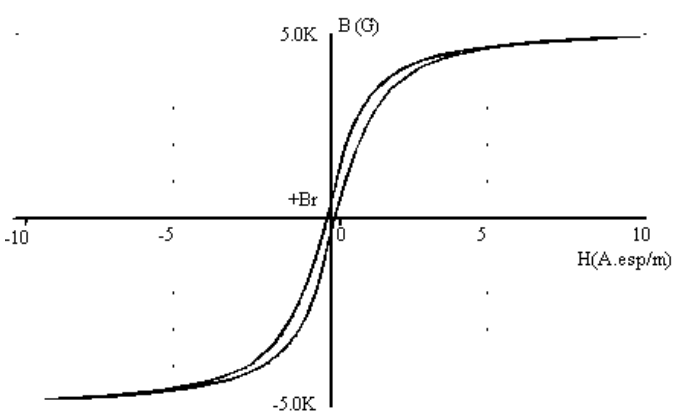

Figura 3 - Curva de magnetização de sensor magnético amorfo desenvolvido no LDSM/ON

\section{Discussão e Conclusões}

O LDSM/ON finalmente pode contar com um dispositivo, de precisão, desenvolvido internamente e que vai auxiliar na determinação das curvas de magnetização para desenvolvimento de sensores magnéticos, de alta resolução, amorfos e nanocristalinos.

\section{Agradecimentos}

Ao CNPq pela bolsa PCl, no Observatório Nacional, à primeira autora.

\section{Referências}

Almeida, A.M. L et al de 2010, Medidor virtual para ensaios em materiais magnéticos e transformadores XVIII Congresso Brasileiro de Automática, 12 a 16 setembro/2010.

Branko, K. Milovanovic, A. e Djekic, M de 2009Determination of characteristics of ferromagnetic material using modern data acquisition system. Serbian Journal of Electrical Engineering. Vol. 6, N. 3 pag 451-459. 